\title{
Wet-Chemical Approaches for Atomic Layer Etching of Semiconductors: Surface Chemistry, Oxide Removal and Reoxidation of InAs (100)
}

\author{
Dennis H. van Dorp, ${ }^{\mathrm{a}, \mathrm{z}}$ Sophia Arnauts, ${ }^{\mathrm{a}}$ Frank Holsteyns, ${ }^{\mathrm{a}}$ and Stefan De Gendt ${ }^{\mathrm{a}, \mathrm{b}, *}$ \\ ${ }^{a}$ Surface and Interface Processing, imec vzw, B-3001 Leuven, Belgium \\ ${ }^{b}$ Departement Chemie, Katholieke Universiteit Leuven, B-3001 Leuven, Belgium
}

\begin{abstract}
An approach for wet-chemical atomic layer etching (WALE) of semiconductors is described. The surface chemistry of InAs was investigated for $\mathrm{HCl} / \mathrm{H}_{2} \mathrm{O}_{2}$ solutions suitable for controlled etching in the low etch rate range $\left(<0.1-10 \mathrm{~nm} \mathrm{~min}^{-1}\right)$. Kinetic studies were performed using inductively coupled plasma - mass spectrometry (ICP-MS). As for GaAs and InGaAs, the importance of the $\mathrm{Cl}^{-}$ion for the etching kinetics is demonstrated and a chemical reaction scheme is presented to help understand the surface chemistry. A detailed study of an alternative two-step etching process was performed. A quantitative ICP-MS analysis of the oxide formed in $\mathrm{O}_{3} / \mathrm{H}_{2} \mathrm{O}$ solution and the dissolution in $\mathrm{HCl}$ was performed suggesting that the removal of oxidized In products is the slow step in the dissolution reaction. The reoxidation of oxide-free InAs (100) surfaces in air is discussed. The etch rate range and the surface morphology control after etching show that the investigated wet-chemical approach for atomic-layer etching is a valid candidate for advanced CMOS processing.

(C) The Author(s) 2015. Published by ECS. This is an open access article distributed under the terms of the Creative Commons Attribution 4.0 License (CC BY, http://creativecommons.org/licenses/by/4.0/), which permits unrestricted reuse of the work in any medium, provided the original work is properly cited. [DOI: 10.1149/2.0081506jss] All rights reserved.
\end{abstract}

Manuscript submitted February 2, 2015; revised manuscript received March 18, 2015. Published April 4, 2015. This paper is part of the JSS Focus Issue on Atomic Layer Etching and Cleaning.

The scaling limit of the Si-based complementary metal-oxide semiconductor (CMOS) technology is rapidly approaching. ${ }^{1}$ The performance enhancement for Si-based transistors can no longer be guaranteed due to intrinsic mobility issues. The considerably higher electron mobility of III-V compound semiconductors (e.g. InGaAs, InAs, InSb) has led to renewed interest and a following phase in the development of future transistors for the 5-7 nm technology node. ${ }^{2}$ For successful integration of these semiconductors on Si platform wafers, many wetchemical processing steps (e.g. bulk material recess, removal of native oxides and metal/particle contamination) are required. Mild etching of the surface is often needed for these purposes. ${ }^{3}$ The aggressive downscaling of the transistor in size requires an ever increasing etching selectivity and ultimately a control at the atomic-layer scale. Since it is well known that the carrier mobility in scaled channel materials is degraded by the surface roughness, ${ }^{4}$ atomically smooth surfaces are targeted after any surface treatment. In addition, the anisotropy in etching is of concern, as different crystal orientations may be exposed simultaneously to the etchant. In order to design wet chemical etchants that allow for appropriate surface conditioning, a thorough understanding of the interactions between the substrate and the chemical solution is therefore required and the underlying etching mechanisms need to be resolved. Furthermore, a kinetically controlled etching process is preferred (i.e. a surface reaction is the rate-limiting step) as hydrodynamic conditions are generally difficult to control, especially for the etching of sub-micron features. ${ }^{5}$

The wet etching of semiconductors generally requires an oxidizing agent in a suitable chemical solution to remove the oxidized surface products. For this form of "open-circuit" dissolution, two types of etching need to be considered. ${ }^{6,7}$ In chemical etching, valence electrons are transferred directly from surface bonds to the oxidizing agent, giving rise to rupture of the bonds and dissolution of the solid. In electroless etching, the oxidizing agent removes electrons from the valence band of the solid; this is equivalent to injection of holes. The holes are mobile and, if localized in surface bonds, cause bond rupture and dissolution. For open-circuit etching of III-V semiconductors $\mathrm{H}_{2} \mathrm{O}_{2}$ is widely used. ${ }^{7-10}$ It has been shown that $\mathrm{HCl} / \mathrm{H}_{2} \mathrm{O}_{2}$ solutions show the lowest degree of anisotropy in etching ${ }^{10,11}$ and are therefore preferred.
In this present work we use $\mathrm{H}_{2} \mathrm{O}_{2}$ in $\mathrm{HCl}$ solution for the etching of InAs in the low etch rate range $\left(<0.1-10 \mathrm{~nm} \mathrm{~min}^{-1}\right)$. This solution has interesting features and allows for controlled etch rates. In most cases the etching of III-V semiconductors follows a chemical mechanism. However, an electrochemical study by Theuwis and Gomes has shown that in the case of InGaAs in $\mathrm{H}_{2} \mathrm{O}_{2} / \mathrm{H}_{2} \mathrm{SO}_{4}$ solution a combined chemical/electroless mechanism operates. ${ }^{12}$ It seems likely that such a mechanism will also operate in the $\mathrm{H}_{2} \mathrm{O}_{2} / \mathrm{HCl}$ case. As we will show, the etching mechanisms for InAs and $\operatorname{In}_{\mathrm{x}} \mathrm{Ga}_{1-\mathrm{x}}$ As are similar and the difference in etch rate between these semiconductors may be attributed to the hole injection rate, which can depend on the position of the valence band edges. This is currently under investigation and beyond the scope of this work.

Although preferred, a kinetically controlled etching process may have an important drawback: in the vicinity of a crystallographic defect (e.g. stacking faults, dislocations), the local etch rate can be higher than that of the bulk (the chemical stability of the defective region is lower). Hence, for defect densities significantly higher than that typically found for bulk materials, the etch process may induce surface roughening as a potential issue. To circumvent this, a twostep etching process can be used. In a first step, a self-limiting oxide is grown. In the second step, the oxide is removed selectively in a suitable wet-chemical solution. This "digital" type of etching allows for highly controlled layer removal. A method was reported by Lin and coworkers. They used a low-power $\mathrm{O}_{2}$ plasma oxidation followed by a diluted $\mathrm{H}_{2} \mathrm{SO}_{4}$ treatment which can etch a combination of InP, InGaAs, and InAlAs in a precise and nonselective manner. ${ }^{13}$ An etch rate of $0.9 \mathrm{~nm} /$ cycle was achieved.

In this paper we are investigating a wet-chemical approach allowing for etching at the atomic-layer-scale (denoted as WALE): a technique similar to that used for the cleaning of Si surfaces. ${ }^{14}$ In this case the surface oxidation is performed in $\mathrm{O}_{3} / \mathrm{H}_{2} \mathrm{O}$ solution followed by native oxide removal in $\mathrm{HCl}$. A detailed and quantitative analysis of the oxide formation process as well as the oxide dissolution kinetics for InAs (100) is reported. Finally, the reoxidation kinetics of an oxide free surface upon air exposure is examined at the sub-atomic-layer scale.

\section{Experimental}

*Electrochemical Society Fellow.

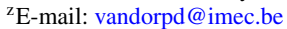

Bulk p-type (100) InAs substrates were purchased at AXT Inc. The 2 inch wafers were $\mathrm{Zn}$ doped $\left(5-20 \mathrm{E} 18 \mathrm{~cm}^{-3}\right)$ and had an etch pit 

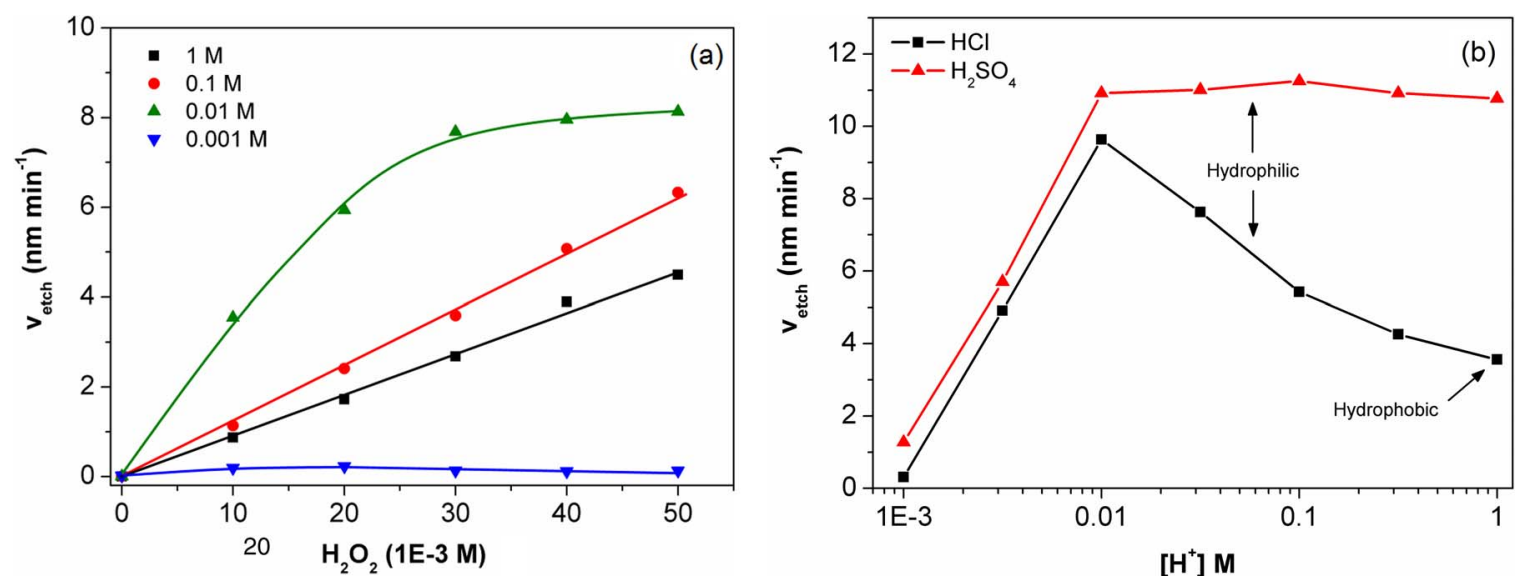

Figure 1. Etch rate of InAs as a function of $\mathrm{H}_{2} \mathrm{O}_{2}$ concentration measured for different $\mathrm{HCl}$ concentrations (a). Dependence of etch rate on the composition of the etchant: $0.02 \mathrm{M} \mathrm{H}_{2} \mathrm{O}_{2}$ in $\mathrm{HCl}$ (black squares) and $\mathrm{H}_{2} \mathrm{SO}_{4}$ (red triangles) for InGaAs. The etch rate is plotted versus $\mathrm{H}^{+}$concentration.

density $<2 \mathrm{E} 4 \mathrm{~cm}^{-2}$. Prior to use, the wafer surface was prepared by immersion in a saturated $\mathrm{O}_{3} / \mathrm{H}_{2} \mathrm{O}$ solution followed by oxide removal in $2 \mathrm{M} \mathrm{HCl}$ and rinsing in ultra-pure water.

Chemicals were purchased from Sigma Aldrich and were of p.a. quality: $37 \% \mathrm{HCl}(12.0 \mathrm{M})$ and $\mathrm{H}_{2} \mathrm{O}_{2}(9.7 \mathrm{M})$.

Etching experiments were performed in a clean room environment using a dedicated Polytetrafluoroethylene (PTFE) etching cell with a Kalrez O-ring to selectively expose $6.16 \mathrm{~cm}^{2}$ of the (100) surface to $100 \mathrm{ml}$ of etching solution. For the oxide removal and reoxidation experiments $10 \mathrm{ml} \mathrm{HCl}$ solution was used. Etch rates were determined by measuring the total amount of dissolved ${ }^{115} \mathrm{In}$ and ${ }^{75} \mathrm{As}$ with inductively coupled plasma - mass spectrometry (ICP-MS, Agilent 7500cs). This technique enables detection of substrate loss at sub-monolayer level assuming bulk density. The measurement error for the etch rate is $<10 \%$ under these conditions. ${ }^{15}$

Wetting properties were determined by depositing $3 \mu 1$ Milli-Q water droplets onto the treated InAs surface. Side-view images were recorded with an optical microscope. The contact angle was analyzed using a DataPhysics OCA 230L Contact Angle System. The average value for the different treatments was determined by measuring at least three different positions on the wafer.

Surface composition during reoxidation in air for an oxide free surface was studied by X-ray photoelectron spectroscopy (XPS) measurements. A Theta300 system from ThermoInstruments was used equipped with a monochromatized $\mathrm{Al} \mathrm{K} \alpha \mathrm{X}$-ray source $(1486.6 \mathrm{eV})$. The exit angle was 22 degrees as measured with respect to the normal of the sample and the spot diameter was 400 microns.

\section{Results and Discussion}

Chemical etching in $\mathrm{HCl} / \mathrm{H}_{2} \mathrm{O}_{2}$ solution.- Figure 1 shows the influence of the $\mathrm{H}_{2} \mathrm{O}_{2}$ concentration on the etch rate for InAs (100) in $0.001-1 \mathrm{M} \mathrm{HCl}$ solution. The etch rate $\left(\mathrm{v}_{\text {etch }}\right)$ is low for $0.001 \mathrm{M}$ $\mathrm{HCl}$ over the whole $\mathrm{H}_{2} \mathrm{O}_{2}$ concentration range $\left(\sim 0.2 \mathrm{~nm} \mathrm{~min}{ }^{-1}\right)$. Poor solubility of the oxidized products results in "passivation" of the surface. At this $\mathrm{pH}$, dissolution is limited by the solubility of oxidized group III species. ${ }^{16}$ The solubility increases rapidly when the $\mathrm{HCl}$ concentration is increased to $0.01 \mathrm{M}$ and the compound semiconductor is etched. Two etching regimes can be distinguished. For $\leq 0.02 \mathrm{M} \mathrm{H}_{2} \mathrm{O}_{2}$, the etch rate increases linearly with increasing concentration of the oxidizing agent, while at higher concentration $(>0.02 \mathrm{M})$ the etch rate levels off to a value of $8.0 \mathrm{~nm} \mathrm{~min} \mathrm{~m}^{-1}$. The latter case, can be explained by a kinetic effect; desorption of oxidized group III products limits the reaction rate. ${ }^{8}$ A lower etch rate is observed that increases linearly with increasing $\mathrm{H}_{2} \mathrm{O}_{2}$ concentration for a higher $\mathrm{HCl}$ concentration of $0.1 \mathrm{M}$. The etch rate decreases further when the $\mathrm{HCl}$ concentration is increased to $1 \mathrm{M}$. For $<0.005 \mathrm{M} \mathrm{H}_{2} \mathrm{O}_{2}$, etch rates on the atomic-layer scale are achieved and the dissolution of the semiconductor is under full kinetic control.

It was observed that the decrease in etch rate with increasing $\mathrm{HCl}$ concentration is accompanied by a marked change in the wetting properties of the semiconductor; the surface is hydrophobic for a $\mathrm{HCl}$ concentration $\geq 1 \mathrm{M}$ while below $1 \mathrm{M} \mathrm{HCl}$ it is hydrophilic. This surprising trend was recently also demonstrated for InGaAs and GaAs. ${ }^{17}$ The marked change in wetting properties of the semiconductor could be related to either to $\mathrm{H}^{+}$or $\mathrm{Cl}^{-}$. We were able to exclude the importance of $\mathrm{H}^{+}$on the dissolution of III-As by etching experiments in $\mathrm{H}_{2} \mathrm{SO}_{4} / 0.02 \mathrm{M} \mathrm{H}_{2} \mathrm{O}_{2}$. This is demonstrated in Figure $1 \mathrm{~b}$, which shows the dependence of the etch rate for InGaAs on the $\mathrm{H}_{2} \mathrm{SO}_{4}$ concentration for a $0.02 \mathrm{M} \mathrm{H}_{2} \mathrm{O}_{2}$ solution (red triangles). The etch rate is plotted versus the $\mathrm{H}^{+}$concentration given on a log-scale. In the range $0.001-0.01 \mathrm{M} \mathrm{HCl}$, a substantial increase in $\mathrm{v}_{\mathrm{etch}}$ is observed from $1.3 \mathrm{~nm} \mathrm{~min}-1$ to $10.9 \mathrm{~nm} \mathrm{~min}{ }^{-1}$ due to an increase in the solubility of the oxidized group III products (the solubility of oxidized As species is high over the whole $\mathrm{pH}$ range).$^{16}$ For the $\mathrm{H}^{+}$range $0.01-1 \mathrm{M}$ a hydrophilic surface was observed and the etch rate was constant. This etch rate is comparable to that found for the $0.01 \mathrm{M} \mathrm{HCl}$ solution. The marked change in wetting properties and the gradual decrease in $\mathrm{v}_{\text {etch }}$ from 9.8 to $3.6 \mathrm{~nm} \mathrm{~min}{ }^{-1}$ in the range $0.01-1 \mathrm{M} \mathrm{HCl}$ points to the importance of $\mathrm{Cl}$ at the surface. Total Reflection X-ray Fluorescence measurements could be used to support the observations. Other XPS studies attributed the hydrophobicity of GaAs (100) surfaces to $\mathrm{Cl}$ termination. ${ }^{18,19}$ For GaAs (111) the importance of $\mathrm{Cl}$ was also shown. ${ }^{20,21}$

The strong effect of the anion on the etching behavior formed the basis of a dissolution model we developed. A schematic overview of the chemical etching mechanism for InAs in $\mathrm{HCl} / \mathrm{H}_{2} \mathrm{O}_{2}$ solution is given in Figure 2. The first etching step involves chemical attack by $\mathrm{H}_{2} \mathrm{O}_{2}$ on the In-As surface bond via a synchronous exchange of bonds; the original $\mathrm{HO}-\mathrm{OH}$ and In-As are replaced by $\mathrm{In}-\mathrm{OH}$ and As-OH. ${ }^{6-8}$ It is generally assumed that breaking the first bond at the surface is the slow step in oxidation reactions. ${ }^{22,23}$ At high $\mathrm{HCl}$ concentration reaction 2A occurs: the replacement of surface $\mathrm{OH}$ by nucleophilic attack of the $\mathrm{Cl}^{-}$on the polarized surface bond is faster than the rupture of the back bond (see inset $2 \mathrm{~A}$ ). $\mathrm{Cl}$ termination renders the surface hydrophobic. The weaker electronegativity of $\mathrm{Cl}$ with respect to $\mathrm{O}$ leads to a stabilization of the back bond. The surface is stabilized and the $\mathrm{v}_{\text {etch }}$ lowered. Further oxidation of the back bonds results in the formation of surface products (reaction $2 \mathrm{~B}$ ). For medium $\mathrm{HCl}$ concentration reaction $2 \mathrm{~A}$ is not important. The surface is mainly $\mathrm{OH}$ terminated and hydrophilic. The larger back bond destabilization results in a higher $\mathrm{v}_{\text {etch }}$ (reaction 3). At medium and high $\mathrm{HCl}$ concentration the rate of dissolution of the surface products is fast (reaction $4 \mathrm{~A} / \mathrm{B}$ ). This is not so for low $\mathrm{HCl}$ concentration (reaction $4 \mathrm{C}$ ). The rate of dissolution is lower than the rate of oxide formation. This gives rise to passivation 


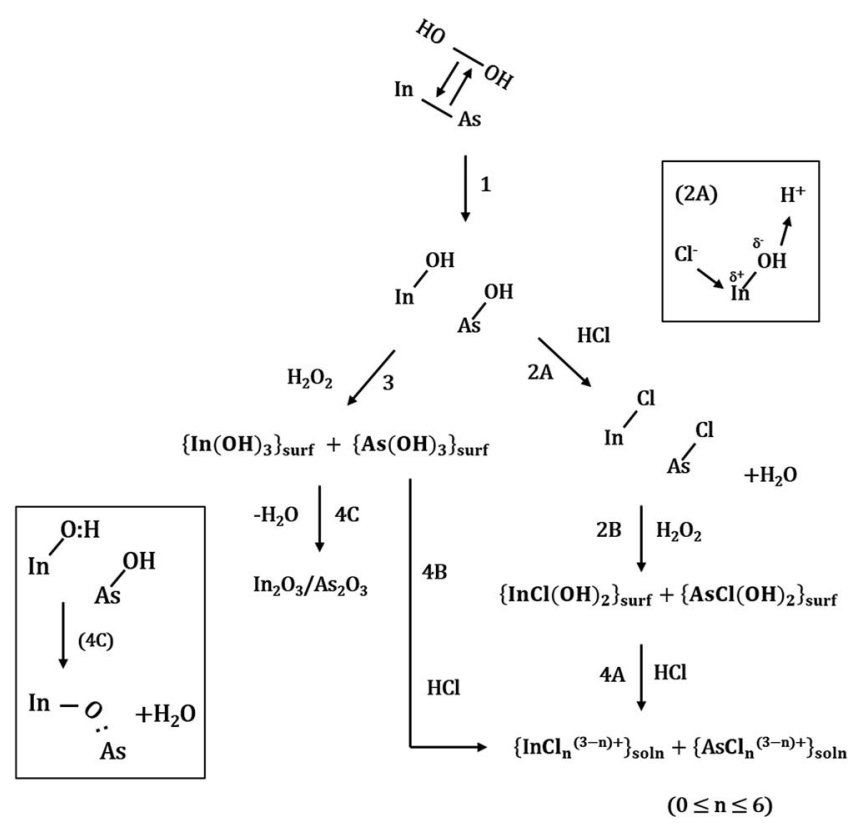

Figure 2. Schematic overview of the chemical etching mechanism of InAs in $\mathrm{HCl} / \mathrm{H}_{2} \mathrm{O}_{2}$ solution.

of the surface under removal of water (inset 4C). Very likely a mixed oxide is formed.

As discussed earlier, electroless reactions between the oxidizing agent and the semiconductor may be essential to understand surface stoichiometry after etching. For instance, such a mechanism can cause preferential oxidation of the group (III) element and consequently results in the formation of a group $\mathrm{V}$ rich layer. ${ }^{24-27}$

AFM measurements showed an increase in surface roughening after etching InAs (100): the RMS value increased from $0.37 \mathrm{~nm}$ for the untreated (as-recieved) wafer to $0.69 \mathrm{~nm}$ after $10 \mathrm{~nm}$ of etching in $1 \mathrm{M} \mathrm{HCl} / 0.01 \mathrm{M} \mathrm{H}_{2} \mathrm{O}_{2}$ solution. The observed surface roughening is attributed to the presence of reactive surface sites. ${ }^{17}$ These sites can be effectively passivated by increasing the $\mathrm{Cl}^{-}$content and results in a smooth surface finish: for $6 \mathrm{M} \mathrm{HCl} / 0.01 \mathrm{M} \mathrm{H}_{2} \mathrm{O}_{2}$, an RMS value of $0.28 \mathrm{~nm}$ was measured for InAs after $10 \mathrm{~nm}$ of etching. The importance of $\mathrm{Cl}^{-}$for surface passivation during a wet-chemical epitaxial lift off for $\mathrm{GaAs}$ was also suggested by Cheng and co-workers. ${ }^{28}$

Chemical etching in $\mathrm{HCl}$ solution. - No significant etching occurs when InAs is exposed to $\leq 8 \mathrm{M} \mathrm{HCl}$ solution; $\mathrm{v}_{\text {etch }}$ is $\sim 0.1 \AA \mathrm{min}^{-1}$ (Figure 3, top). This concentration range allows for (highly) selective oxide removal. The etch rate increases rapidly to $20 \mathrm{~nm} \mathrm{~min}{ }^{-1}$ for $10 \mathrm{M} \mathrm{HCl}$ and $1.1 \mu \mathrm{m} / \mathrm{min}$ at $12 \mathrm{M} \mathrm{HCl}$. For comparison, InP etches at much lower $\mathrm{HCl}$ concentration $(>2 \mathrm{M})$. The mechanism of the chemical dissolution of semiconductors was initially proposed for symmetric chemical etchants. ${ }^{29}$ Later Notten extended the model to asymmetric chemical etchants by showing that InP is etched by molecular $\mathrm{HCl}^{30}$ and $\mathrm{HBr}^{31}$ species. A similar dissolution mechanism is expected for InAs. The first etching step involves coordination of the molecule to the surface (Figure 3, bottom). A synchronous exchange of bonds occurs resulting in In-Cl and As-H surface bonds $\left(\mathrm{k}_{1}\right)$. Subsequently, the remaining surface bonds are broken in analogous way to remove the group III and group V atoms from the lattice. Soluble $\mathrm{InCl}_{3}$ complexes are formed and arsine gas is evolved. By contrast, $\mathrm{GaAs}$ and $\mathrm{InGaAs}$ are chemically stable in $\mathrm{HCl}$ at room temperature. This indicates that surface reaction kinetics may be important.

Although the described etching behavior in $\mathrm{HCl}$ solution can be exploited for layer selective etching purposes as was recently demonstrated for the fabrication of gate-all-around nanowire devices ${ }^{32}$ and the formation of nanogaps in InAs nanowires, ${ }^{33}$ the use of $\mathrm{HCl}$ for atomic layer etching applications is not preferred. Highly anisotropic
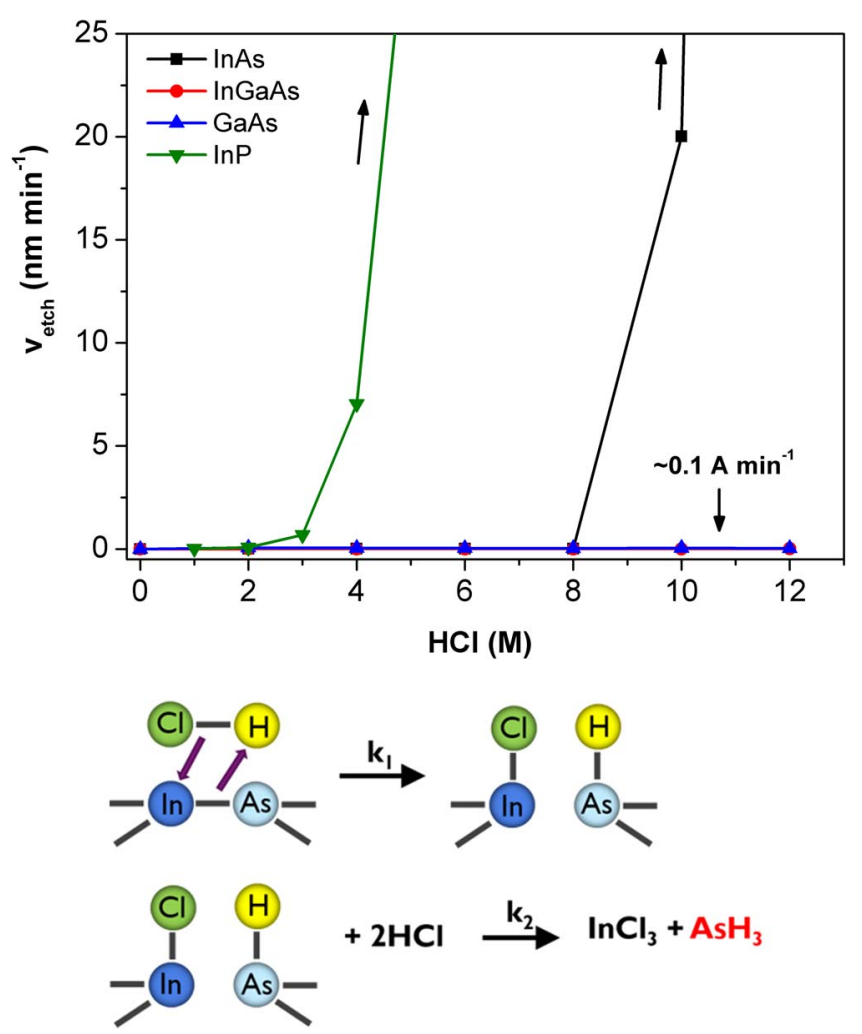

Figure 3. Etch rate of InAs (100) as a function of $\mathrm{HCl}$ concentration (top). InGaAs, GaAs and InP have been added for comparison. Schematic representation of the etching mechanism of $\mathrm{InAs}$ in $\mathrm{HCl}$ solution (bottom), reproduced after Notten. ${ }^{30}$

etching behavior, as evidenced by the formation of distinct etching pits, induces significant surface roughening. ${ }^{34}$ In addition, formation of highly toxic $\mathrm{AsH}_{3}$ is of important concern. Recently we demonstrated that these issues can be circumvented by using an oxidizing agent in the chemical solution. ${ }^{11}$

Two-step etching process: wet-chemical oxide formation and dissolution.- Wetting of (100) GaAs and InGaAs surfaces after immersion in $\mathrm{HCl}$ solution has been investigated by contact angle $\left(\theta_{\mathrm{c}}\right)$ measurements. ${ }^{17,18,35}$ The surface is hydrophilic $\left(\theta_{c}<5^{\circ}\right)$ when it is covered by the native oxide. After oxide dissolution the surface becomes hydrophobic with a contact angle in the range of $60-70^{\circ}$ at room temperature.

We studied the removal of native oxide from InAs in $\mathrm{HCl}$ solution, by also measuring the contact angle after immersion. The wafer was immersed for 10 minutes in a saturated $\mathrm{O}_{3} / \mathrm{H}_{2} \mathrm{O}$ solution. The presence of the strong oxidizing agent results in a chemical reaction with the formation of In(III) and As(III)/As(V) oxides:

$$
\begin{gathered}
2 \mathrm{InAs}+2 \mathrm{O}_{3} \rightarrow \mathrm{In}_{2} \mathrm{O}_{3}+\mathrm{As}_{2} \mathrm{O}_{3} \\
2 \mathrm{InAs}+3 \mathrm{O}_{3} \rightarrow \mathrm{In}_{2} \mathrm{O}_{3}+\mathrm{As}_{2} \mathrm{O}_{5}+1 / 2 \mathrm{O}_{2}
\end{gathered}
$$

Figure $4 \mathrm{a}$ shows $\theta_{\mathrm{c}}$ as a function of immersion time for InAs and two $\mathrm{HCl}$ concentrations. The as-prepared sample with the oxide has a good wetting behavior as evidenced by the very low contact angle. $\theta_{\mathrm{c}}$ shows a strong increase after 2 minutes of immersion in $2 \mathrm{M}$ $\mathrm{HCl}$ followed by a gradual increase to $55^{\circ}$ after 25 minutes. For the lower $\mathrm{HCl}$ concentration a comparable trend is observed. The lower contact angle suggests that the removal of the oxide is less effective. A maximum $\theta_{c}$ of $60^{\circ}$ was observed after 60 minutes of immersion. This indicates that the oxide removal on InAs is difficult, as suggested earlier by Losurdo and coworkers. ${ }^{36}$ In contrast, the maximum value 

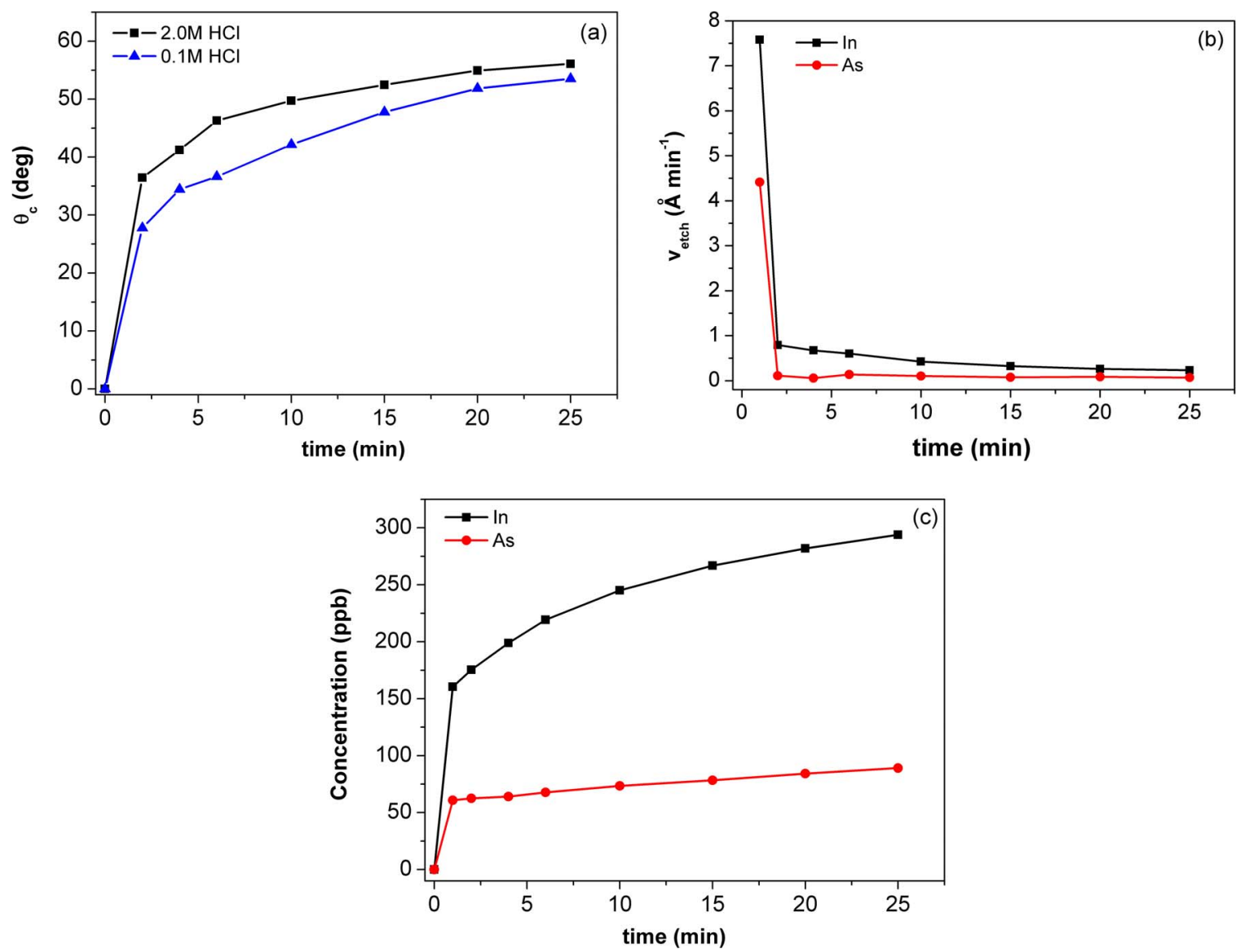

Figure 4. (a) Influence of immersion time in $\mathrm{HCl}$ solution on the contact angle of an oxidized InAs surface. Two $\mathrm{HCl}$ concentrations are shown. (b) Etch rate for InAs as function of immersion time in $2 \mathrm{M} \mathrm{HCl}$. Bulk etch rates were calculated using the In (black squares) and As concentration. ${ }^{15}$ (c) In and As concentrations plotted cumulative as function of immersion time in $2 \mathrm{M} \mathrm{HCl}$.

of $\theta_{\mathrm{c}}$ was reached much faster for GaAs and InGaAs, indicating a much higher oxide solubility.

Quantitative information on the oxide formation and the oxide dissolution kinetics could be obtained by analyzing the etchant composition during oxide removal by ICP-MS. In the case of an oxide free InAs (100) surface, chemical etching leads to stoichiometric dissolution of the semiconductor with an etch rate of $\sim 0.1 \AA \mathrm{min}^{-1}$ (Figure 3 ). As long as a native oxide is present on the surface, the etch rate will be higher than this value. In Figure $4 \mathrm{~b}$ the etch rate is given as function of immersion time in $2 \mathrm{M} \mathrm{HCl}$ solution for the $\mathrm{O}_{3} / \mathrm{H}_{2} \mathrm{O}$ treated starting surface. The etch rates calculated from the As concentration suggest that the arsenic oxides are removed within 1 minute. By contrast, the formed indium oxides are far more resistant as evidenced by the slow decrease in etch rate for $\geq 2$ min of immersion. After 25 minutes the etch rate is still a factor 2 higher than the background etch rate indicating that the oxide product is not fully removed within this time frame. This indicates that the removal of the In oxidation products is the slow step in the dissolution reaction. After 60 minutes the etch rates were equal; the oxide is fully removed which is supported by the contact angle measurements. Figure $4 \mathrm{c}$ shows the measured In and As concentration, corrected for the background values found for the oxide free surface, plotted cumulatively as function of time. The trend observed for the total In concentration (black squares) is comparable to that for the contact angle. The strong initial increase in the In content corresponds to the removal of 2.5 equivalent monolayers of oxidized InAs within the first minute. Subsequently, the increase in the In concentration levels off and the remaining oxide is removed at a lower rate. Approximately 4.6 equivalent monolayers dissolve during the first 25 minutes. This is about $95 \%$ of the total indium surface oxide. Our data suggest that the last equivalent monolayer is removed in 50 minutes which corresponds to an increase in $\theta_{\mathrm{c}}$ from $50^{\circ}$ to $60^{\circ}$. By calculating the equivalent thickness from the measured As concentration, insight in the oxide stoichiometry could be obtained. Approximately $50 \%$ of the expected As content was detected. This points to a nonstoichiometric oxide layer after the $\mathrm{O}_{3} / \mathrm{H}_{2} \mathrm{O}$ treatment and is attributed the amphoteric properties of the arsenic oxide which dissolves in water and in solutions of $\mathrm{pH}$ between 1 and $8 .{ }^{16}$ Under these conditions the etch rate amounts to $\sim 1.4 \mathrm{~nm} /$ cycle. The reported oxide thickness for an $\mathrm{O}_{3} / \mathrm{H}_{2} \mathrm{O}$ treatment is in good agreement with the native oxide thickness measured by spectroscopic ellipsometry. ${ }^{36}$ Further optimization of the oxidation step is required to reduce the material loss to the single atomic-layer range. AFM measurements indicated no significant surface roughening after 1 cycle.

Reoxidation kinetics for an oxide free InAs (100) surface upon air exposure were investigated. Prior to each experiment, the $\mathrm{O}_{3} / \mathrm{H}_{2} \mathrm{O}$ treated wafer was immersed for 60 minutes in $2 \mathrm{M} \mathrm{HCl}$ solution resulting in a (predominantly) Cl-terminated surface (see references. ${ }^{21-25}$ The air-grown oxide was dissolved in $2 \mathrm{M} \mathrm{HCl}$ solution and the composition of the etchant was analyzed by ICP-MS. Figure 5a shows the measured In and As concentration as function of air exposure time. Both elemental concentrations gradually increase with increasing time. Although $\mathrm{Cl}$ proved to have passivating properties in our etching experiments, the semiconductor surface is not stable in air.

The observed trend for the In concentration suggests that an equivalent of up to 0.2 monolayer of InAs is oxidized during the first 10 minutes of air exposure. The oxide thickness increases gradually and approximately 0.7 monolayer of oxide is formed after 60 minutes of air exposure. It is noted that $\theta_{\mathrm{c}}$ decreased from $60^{\circ}$ to $50^{\circ}$ after 1 hour of air exposure, which is in good agreement with the oxide removal 

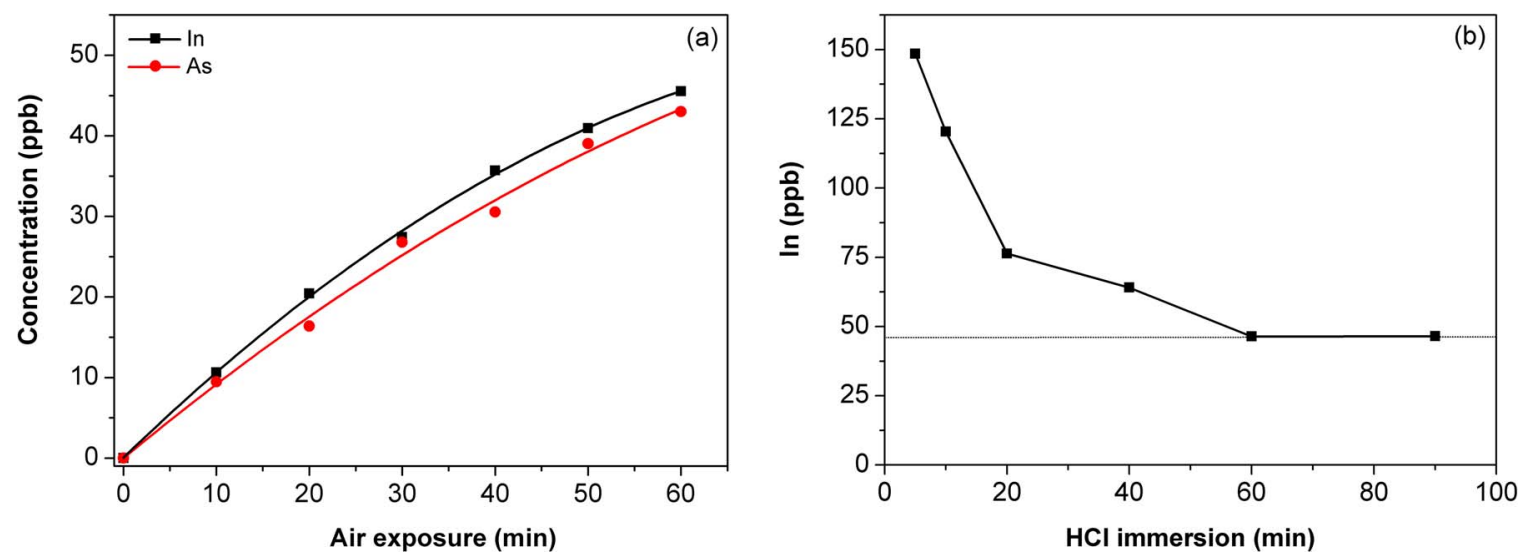

Figure 5. Measured In and As concentrations as function of air exposure time for an oxide free InAs (100) surface (a). Measured In concentrations after 1 hour of air exposure as function of $\mathrm{HCl}$ immersion time (b).

\begin{tabular}{lcc}
\hline $\begin{array}{l}\text { Table I. Atomic concentrations measured by angle integrated XPS } \\
\text { measurements. }\end{array}$ & In & As \\
Angle Integrated (a.u.) & 0.50 & 0.50 \\
\hline Bulk (expected) & 0.34 & 0.66 \\
5 minutes & 0.34 & 0.66 \\
15 minutes & 0.36 & 0.64 \\
35 minutes & 0.37 & 0.63 \\
45 minutes & 0.38 & 0.62 \\
65 minutes &
\end{tabular}

experiments shown in Figure 4. In contrast, the total amount of As is somewhat higher than it would be expected for a stoichiometric oxide, 1.0 and 0.7 equivalent monolayer respectively. This observation is attributed to an additional oxidation of elemental As present at the surface originating from the oxide removal step in $\mathrm{HCl}$ solution. Arsenic enrichment in acidic solutions has been also observed for InGaAs ${ }^{37}$ and GaAs. ${ }^{38,39}$ With angle integrated XPS measurements, we have demonstrated that the zero-valent As is formed on the InAs
(100) surface as well: measuring the surface composition after various air exposure times revealed an excess of the element (Table I). The dissolution rate of the elemental As is expected to be low.

The influence of the $\mathrm{HCl}$ immersion time on the reoxidation kinetics was studied. After the $\mathrm{O}_{3} / \mathrm{H}_{2} \mathrm{O}$ treatment and $\mathrm{HCl}$ immersion, the wafer was exposed to air for 60 minutes and the total amount of oxidized In was quantified (Figure 5b). As expected, a decrease of the In concentration with increasing immersion time was observed. For $\geq 60$ minutes of $\mathrm{HCl}$ treatment, the In concentration was found to be constant; the formed oxide is solely related to the air exposure. These results confirm that minimum 1 hour is required to remove the native oxide on InAs effectively.

Surface oxidation was further examined by analyzing the XPS spectra measured at a fixed angle of $78^{\circ}$. Figure 6 shows the As $3 \mathrm{~d}$ (a-e) and In $3 d_{5 / 2}$ spectra (f) for various air exposure times. The As $3 d$ spectrum shows an oxidized As peak at a binding energy of $44.5 \mathrm{eV}$. The oxide peak is visible after exposing the wafer to air for a minimum of 5 minutes. This result is in good agreement with the ICP-MS data discussed above. The pronounced increase in the peak intensity with increasing air exposure time shows that the As oxidation occurs progressively in time. The interpretation of the In $3 \mathrm{~d}_{5 / 2}$ spectrum is
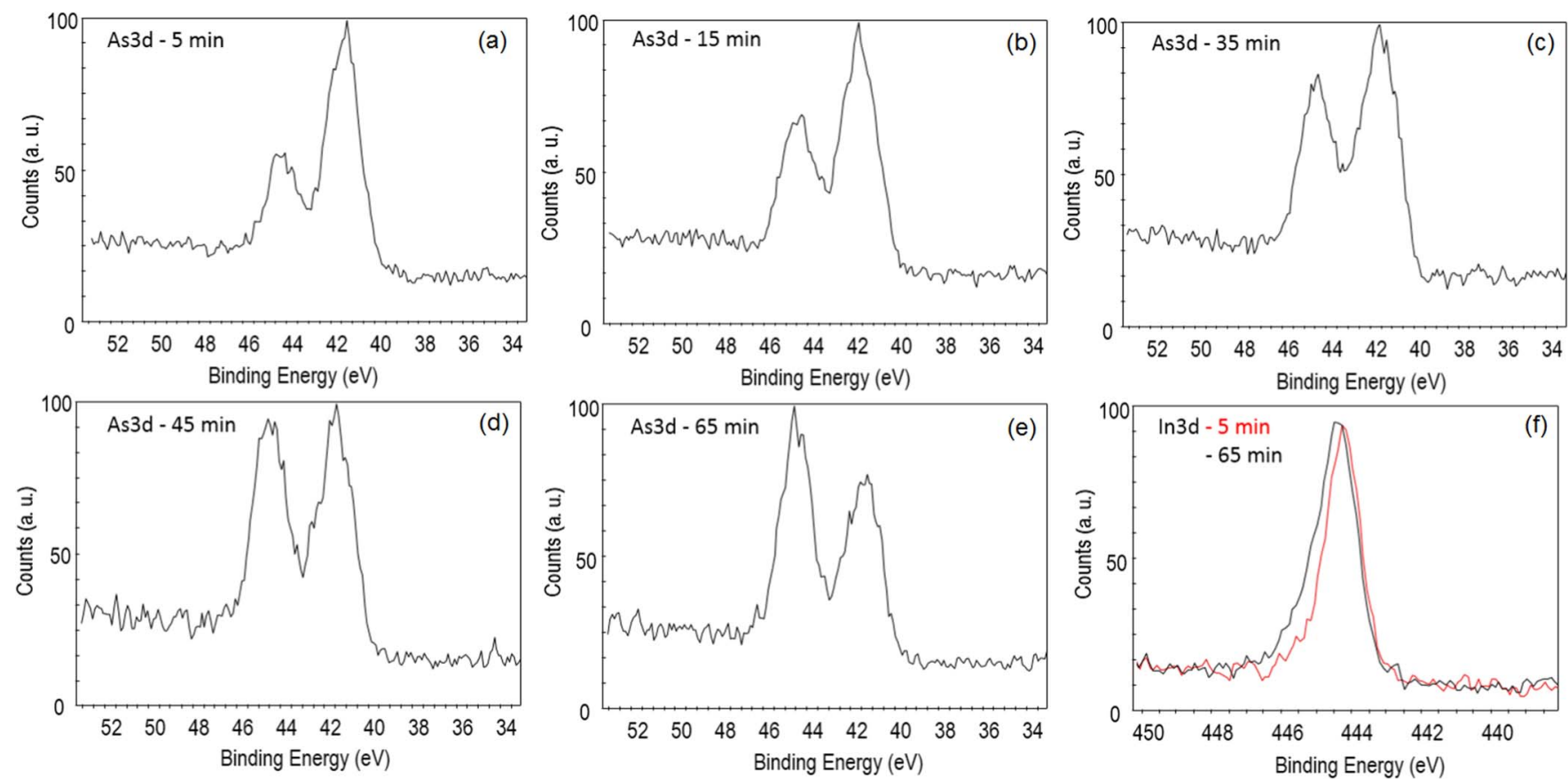

Figure 6. XPS spectra showing the As $3 \mathrm{~d}$ and the In $3 \mathrm{~d} 5 / 2$ peaks of InAs for various air exposure times after native oxide removal in $2 \mathrm{M} \mathrm{HCl}$ for $60 \mathrm{minutes}$. 
difficult due to the small chemical shift of the $\operatorname{In}^{3+}$ peak with respect to the substrate peak. In this case the asymmetry of the peak points to the presence of oxides. A clear increase in asymmetry of the In peak is observed after 60 minutes of air exposure.

\section{Conclusions}

The surface chemistry of InAs (100) was investigated for $\mathrm{HCl} / \mathrm{H}_{2} \mathrm{O}_{2}$ solutions suitable for controlled etching in the atomiclayer-range. Kinetic studies were performed using ICP-MS. The semiconductor can be etched in $>0.001 \mathrm{M} \mathrm{HCl}$; at lower concentration surface passivation occurs due to the limited solubility of oxidized In products. In the higher $\mathrm{HCl}$ concentration range, the etch rate increases with increasing $\mathrm{H}_{2} \mathrm{O}_{2}$ concentration. It was demonstrated that the etch rate strongly depends on the presence of $\mathrm{Cl}^{-}$(and not $\mathrm{H}^{+}$), and decreases with increasing $\mathrm{HCl}$ concentration; this is accompanied by a marked change in the wetting properties of the semiconductor. Hydrophilic surfaces are observed for concentrations $<1 \mathrm{M} \mathrm{HCl}$ while for $\geq 1 \mathrm{M} \mathrm{HCl}$ the surface is hydrophobic. This is attributed to chlorine termination of the surface. Furthermore, the solution composition can be used to control the surface morphology. A chemical reaction scheme is presented which describes the surface chemistry of InAs in $\mathrm{HCl} / \mathrm{H}_{2} \mathrm{O}_{2}$ solution.

InAs (100) surfaces are chemically stable in $\leq 8 \mathrm{M} \mathrm{HCl}$ solution. At higher $\mathrm{HCl}$ concentration the semiconductor is etched chemically and significant surface roughening occurs.

A detailed study of an alternative two-step etching process was performed. Dissolution kinetics of a surface oxide formed by $\mathrm{O}_{3} / \mathrm{H}_{2} \mathrm{O}$ treatment were studied for $\mathrm{HCl}$ solution. Contact angle and ICP-MS measurements show a comparable trend: the oxide removal rate in 2 $\mathrm{M} \mathrm{HCl}$ is low and quantitative analysis of the etchant indicates that the removal of oxidized In products is the slow step in the dissolution reaction; 60 minutes are required to dissolve the oxide. Group V oxide products are highly soluble and removed within 1 minute.

Reoxidation of an oxide free InAs (100) was examined by ICP-MS at the sub-atomic-layer-scale. The surface is not stable toward oxidation in air. Up to 0.2 equivalent monolayer of oxidized In-As were detected after 10 minutes of air exposure. The oxide thickness increases gradually and approximately 0.7 monolayer of oxide is formed after 60 minutes of air exposure.

Angle integrated XPS measurements were used to study the surface composition. Elemental arsenic is formed on the InAs (100) surface during the oxide removal step in $\mathrm{HCl}$ solution. XPS spectra show a clear increase in the oxidized As peak and the asymmetry of In peak with increasing air exposure time. These results in good agreement with the ICP-MS measurements.

The etch rate range and the surface morphology control after etching show that the investigated wet-chemical approach for atomic-layer etching is a valid candidate for advanced CMOS processing.

\section{Acknowledgments}

This work is part of the IMEC Industrial Affiliation Program on Ge/III-V devices. The authors acknowledge Screen Semiconductor Solutions Co. Ltd., Entegris ATMI, Kurita and Fuji Film Electronic Materials for their contributions to the Joint Development Program,
Alain Moussa for the AFM measurements, Thierry Conard for the XPS measurements and Daniel Cuypers and John Kelly (Utrecht University) for the useful discussions.

\section{References}

1. International Technology Roadmap for Semiconductors, see www.itrs.net

2. J. A. del Alamo, Nature, 479, 317 (2011).

3. K. A. Reinhardt and R. F. Reidy, Handbook of Cleaning for Semiconductor Manufacturing - fundamentals and application, Wiley, U.S.A. (2011).

4. S. Deleonibus, Electronic Devices Architectures for the NANO-CMOS Era, Pan Stanford Publishing PTE LTD (2008).

5. V. B. Svetovoy, J. W. Berenschot, and M. C. Elwenspoek, J. Electrochem. Soc., 153, C641 (2006).

6. P. H. L. Notten, J. E. A. M. van den Meerakker, and J. J. Kelly, Etching of III-V Semiconductors: an Electrochemical Approach, Elsevier Advanced Technology Oxford 1991.

7. P. H. L. Notten, J. J. Kelly, and H. K. Kuiken, J. Electrochem. Soc., 133, 1226 (1986).

8. J. J. Kelly and A. C. Reynders, Appl. Surf. Sci., 29, 149 (1987)

9. A. R. Clawson, Mater. Sci. Eng., 31, 1 (2001).

10. D. W. Shaw, J. Electrochem. Soc., 128, 874 (1981).

11. D. Cuypers, S. De Gendt, S. Arnauts, K. Paulussen, and D. H. van Dorp, ECS J. Solid State Sci. Technol., 2, 185 (2013).

12. A. Theuwis and P. Gomes, J. Electrochem. Soc., 144, 1390 (1997).

13. J. Lin, X. Zhao, D. A. Antoniadis, and J. A. del Alamo, IEEE EDL, 35(4), 440 (2014).

14. T. Hattori, T. Osaka, A. Okamoto, K. Saga, and H. Kuniyasu, J. Electrochem. Soc., 145, 3278 (1998).

15. J. Rip, D. Cuypers, S. Arnauts, F. Holsteyns, D. H. van Dorp, and S. De Gendt, ECS J. Solid State Sci. Technol., 3, N3064 (2014).

16. M. Pourbaix, Atlas of Electrochemical Equilibria in Aqueous Solutions, Cebelcor (1974).

17. D. H. van Dorp, S. Arnauts, D. Cuypers, J. Rip, F. Holsteyns, S. De Gendt, and J. J. Kelly, ECS J. Solid State Sci. Technol., 3(6), P179 (2014).

18. S. Osakabe and S. Adachi, Jpn. J. Appl. Phys., 36, 7119 (1997).

19. Z. H. Lu, F. Chatenoud, M. M. Dion, M. J. Graham, H. E. Ruda, I. Koutzarov, Q. Liu, C. E. J. Mitchell, I. G. Hill, and A. B. McLean, Appl. Phys. Lett., 67, 670 (1995)

20. Z. Song, S. Shogen, M. Kawasaki, and I. Suemune, J. Vac. Sci. Technol. B, 13, 77 (1995).

21. S. L. Peczonczyk, J. Mukherjee, A. I. Carim, and S. Maldonado, Langmuir, 28, 4672 (2012).

22. H. Gerischer and W. Mindt, Electrochim. Acta, 13, 1329, (1968).

23. K. W. Frese, M. J. Madou, and S. R. Morrison, J. Phys. Chem., 84, 3172 (1980).

24. R. Memming and G. Schwandt, Electrochim. Acta, 13, 1299, (1986).

25. E. K. Propst, K. W. Vogt, and P. A. Kohl, J. Electrochem. Soc., 140, 3631 (1993).

26. N. J. Smeenk, J. Engle, P. Muler, G. J. Bauhuis, G. M. M. W. Bissels, J. J. Schermer, E. Vlieg, and J. J. Kelly, ECS J. Solid State Sci. Technol., 2, P58 (2013).

27. M. V. Lebedev, W. Calvet, T. Mayer, and W. Jaegermann, J. Phys. Chem. C. 118 (24), $12774(2014)$

28. C. W. Cheng, K. T. Shiu, N. Li, SJ. Han, L. Shi, and D. K. Sadana, Nature Communications, 4, 1 (2013).

29. H. Gerisher and I. Wallem-Mattes, Z. Phys. Chem. (NF) 64, 187 (1969)

30. P. H. L. Notten, J. Electrochem. Soc., 131, 2641 (1984).

31. P. H. L. Notten and A. A. J. M. Damen, Appl. Surf. Sci. 28, 331 (1987).

32. N. Waldron, C. Merckling, L. Teugels, P. Ong, S. A. U. Ibrahim, F. Sebaai, A. Pourghaderi, K. Barla, N. Collaert, and A. V. Y. Thean, IEEE Electron. Device Lett., 35(11), 1097 (2014).

33. I. Schukfeh, K. Storm, A. Hansen, C. Thelander, P. Hinze, A. Beyer, T. Weimann, L. Samuelson, and M. Tornow, Nanotechnology 25, 465306M (2014).

34. D. H. van Dorp, D. Cuypers, S. Arnauts, A. Moussa, L. Rodriguez, and S. De Gendt, ECS J. Solid State Sci. Technol., 2, 190 (2013).

35. K. Matsushita, S. Miyazaki, S. Okuyama, and Y. Kumagai, Jpn. J. Appl. Phys., 33, 4576 (1994).

36. M. Losurdo, M. M. Giangregorio, F. Lisco, P. Capezzuto, G. Bruno, S. D. Wolter, M. Angelo, and A. Brown, J. Electrochem. Soc., 156(4), H263 (2009).

37. Y. Sun, P. Pianetta, PT Chen, M. Kobayashi, Y. Nishi, N. Goel, M. Garner, and W. Tsai, Appl. Phys. Lett., 93, 194103 (2008).

38. Z. Liu, Y. Sun, F. Machuca, P. Pianetta, W. E. Spicer, and R. F. W. Pease, J. Vac. Sci. Technol. A, 21, 212 (2003).

39. M. V. Lebedev, E. Mankel, T. Mayer, and W. Jaegermann, J. Phys. Chem. C. 112(47), 18510 (2008). 